\title{
Characterization of Silver Nanoparticles Synthesizing Bacteria and Its Possible Use in Treatment of Multi Drug Resistant Isolate
}

\author{
Manikant Tripathi, Anil Kumar, Shailendra Kumar* \\ Centre of Excellence, Department of Microbiology (DST-FIST Supported), Dr. Ram Manohar Lohia Avadh University, Faizabad (U.P.), \\ India \\ Email address: \\ shailendra.microbio@gmail.com (S. Kumar) \\ ${ }^{*}$ Corresponding author \\ To cite this article: \\ Manikant Tripathi, Anil Kumar, Shailendra Kumar. Characterization of Silver Nanoparticles Synthesizing Bacteria and Its Possible Use in \\ Treatment of Multi Drug Resistant Isolate. Frontiers in Environmental Microbiology. Vol. 3, No. 4, 2017, pp. $62-67$. \\ doi: $10.11648 /$ j.fem.20170304.12
}

Received: September 30, 2017; Accepted: October 27, 2017; Published: November 25, 2017

\begin{abstract}
Nanobiotechnology is a promising area to cater human life. Biological methods for the synthesis of silver nanoparticles are relatively cost effective process. It was aimed at synthesizing silver nanoparticles using water and soil borne bacterial isolates, characterization of silver nanoparticles using UV-Vis spectroscopy and Fourier transform infra red (FTIR) spectroscopy and its effect on multi drug resistant bacterial isolate. The biosynthesis of silver nanoparticles was evaluated in both bacterial biomass and culture supernatant of Bacillus, Pseudomonas and Escherichia coli in the presence of $1 \mathrm{mM}$ of AgNO3.On the basis of physical appearances of silver nano particles, Pseudomonas sp. was selected for synthesis. The absorbance spectra of reaction mixture of bacterial biomass and supernatant show the strong peak at $420 \mathrm{~nm}$, indicating the presence of silver nanoparticles (AgNPs) using UV-Vis and FTIR spectrophotometry. The influence of synthesized AgNPs was tested against multi drug resistant (MDR) Staphylococcus sp. on Mueller Hinton agar. The multi antibiotics resistant Staphylococcus sp. showed antibiotic sensitivity against the antibiotic discs impregnated with silver nanoparticles. The characteristics of silver nanoparticles revealed its possible use in biomedical field.
\end{abstract}

Keywords: FTIR, MDR, Nanobiotechnology, Pseudomonas sp., Silver Nanoparticle

\section{Introduction}

Bionanotechnologyisan integration of biotechnology and nanotechnology. The idea of nanotechnology was coinedby Professor Richard Feynman [1]. Nanosilver has been used for more than 150 years in the form of colloidal silver, and registered as a biocidal agent in the United States [2]. Silver nitrate is often used as a precursor in the biosynthesis of silver nanoparticles. Silver nanoparticles (AgNPs) has being studied extensively in bionanotechnology mainly due totwomajor reasons, i) it isnon-toxicin nature, (ii) it is safe inorganic antibacterial agent and has ability of killing various kinds of disease causing microbes. Metallic nanoparticles exhibit several unusual optical, thermal, chemical and physical features [3]. Nanoparticles exist in several different morphologies such as spherical, cylindrical, platelets, tubes etc. [4].
Several physicochemical techniques are used to synthesize silver nanoparticles such as chemical reduction, electrochemical method, and photochemical reduction [5-7]. But, these methods have limitations like high operational cost and energy needs which make the synthesis cost competitive. Therefore, in view of these shortcomings of physicochemical methods, a cost-effective and energy efficient alternative for silver nanoparticles synthesis have been adapted using microorganisms [8].

Nowadays research is focused mainly on bacteria as a means of synthesizing nanoparticles due to their abundance, fast growth, easy to cultivate and their ability to adapt under extreme situations. The growth conditions such as temperature, presence of oxygen and incubation time are 
being controlled for the synthesis of metallic nanoparticles [9]. Microbial synthesis of metal nanoparticles occurs either intracellularly or extracellularly. The intracellular synthesis requires biomass of culture. Whereas, when the culture supernatant is treated with aqueous solution of silver nitrate, then it forms silver nanoparticles extracellularly [10]. In the recent past, silver nanoparticles have gainedattention of researchers worldwide due to their potential antimicrobial activities [8, 11-13]. The properties of silver nanoparticles have made them applicable in severalareassuch as biomedical, drug delivery, water treatment, agricultures, etc.[14].

Keeping above in view, the present study was aimed at synthesizing silver nanoparticle using water and soil borne bacterial isolates, characterization of silver nanoparticles using UV-Vis and FTIR spectroscopy techniques and its effect on multi drug resistant bacterial isolates.

\section{Materials and Methods}

\subsection{Sample Collection}

The soil sample was collected fromSaket Dairy, Faizabad and waterfrom Ram kiPaidi, Saryu riverin Ayodhya. The collected water samples were stored in ice box and transported to laboratory for further processing.

\subsection{Isolation, Morphological and Biochemical Characterization of Pseudomonas sp., Escherichia coli and Bacillus sp.}

The bacterial cultures were isolatedon selective mediaviz., King's B agar medium (for Pseudomonas), Mac Conkey agar medium (for E. coli) and Pikovskays agar medium (for Bacillus). The samples were serially diluted following standard serial dilution method. Further, isolation of bacterial was done by inoculating $0.1 \mathrm{ml}$ of diluted samples $\left(10^{-4}, 10^{-5}\right.$ and $\left.10^{-6}\right)$ on selective media in petri dishes following spread plate method. The inoculated Petri dishes were incubated at different temperature (for Bacillus and Pseudomonas at ambient temperature, E. coli at $37^{\circ} \mathrm{C}$ ). The isolated cultures were further identified and characterized in our laboratory using different morphological and biochemical tests as per Bergey's Manual of Determinative Bacteriology [15].

\subsection{Screening of Bacterial Isolates for Silver Nanoparticles Synthesis}

The selected bacterial cultures were inoculated in $500 \mathrm{ml}$ flask containing $250 \mathrm{ml}$ nutrient broth or selected media for the screening of silver nanoparticles synthesizing bacteria, The flasks were incubated in a rotating shaker set at $100 \mathrm{rpm}$ for $48 \mathrm{~h}$ atambient temperature. The culture was centrifuged at $12000 \mathrm{rpm}$ for 10 minutes. The biomass and supernatant were separated and used separately for the synthesis of silver nanoparticles. The supernatant was used for extracellular production and biomass for intracellular production of nanoparticles. The modified method of Shivakrishna et al.
[16] was used for nanoparticle synthesis. Two grams of biomass was added with $1 \mathrm{mM}$ of silver nitrate for the intracellular synthesis, the control set of experiment consisted heat killed biomass added with silver nitrate. The extracellular synthesis of silver nanoparticles was carried out by adding $1 \mathrm{mM}$ of silver nitrate to $99 \mathrm{ml}$ of supernatant, the control set containedonly silver nitrate and $99 \mathrm{ml}$ of distilled water and another set of control for supernatant were used without addition of silver nitrate. The biosynthesis of silver nanoparticles using both biomass and supernatant were separately investigated primarily through the observation of colour change of the experimental sample in the presence of $1 \mathrm{mM}$ of silver nitrate.

\subsection{UV-Visible Spectral and FTIR Analyses}

The synthesized silver nanoparticle was the characterized by UV visible spectrophotometer. FTIR spectroscopy measurements, the biotransformed products present in extracellular filtrate were freeze-dried by lyophilization process and diluted with potassium bromide. The palette of $\mathrm{KBr}$ and $\mathrm{AgNPs}$ was made using $\mathrm{KBr}$ die set and applying hydraulic pressure of 12 tons. The spectrum was recorded on a FT-IR instrument (Thermo Scientific) with diffuse reflectance mode (DRS-800) attachment. All measurements were carried out in the range of $200-7000 \mathrm{~cm}^{-1}$ wavenumbers [17].

\subsection{Effect of Synthesized Nanoparticles on Multi Drug Resistant Bacteria}

The filter sterilized silver nanoparticles were used and impregnated with antibiotic discs. The Staphylococcus culture was spread on Mueller Hinton agar medium (MHA). Treated antibiotic discs were placed on the seeded Mueller Hinton agar medium, and the petri dishes were incubated at $37^{\circ} \mathrm{C}$ for $24 \mathrm{~h}$. The control set of experiment was prepared by same method excluding the antibiotic not treated with SNPs. Following $24 \mathrm{~h}$, the zone of inhibition was measured.

\section{Results and Discussion}

\subsection{Isolation and Biochemical Identification of Nanoparticles Synthesizing Bacteria}

Three different bacterial cultures were isolated on their selective medium after $24 \mathrm{~h}$ of incubation. The colony forming unit (cfu) values of nanoparticles synthesizing bacteriasuch as Bacillus, Pseudomonas and Escherichia coli on different media was calculated as 153, 147 and 132 , respectively in dilution $10^{-4}, 10^{-5}$ and $10^{-6}$. Further bacterial colonies were identified on the basis of their morphological and biochemicalfeatures. The results of morphological and biochemical tests revealed the identity of our efficient isolates as Bacillus, Pseudomonas and E. coli as per Bergey's Manual of Determinative Bacteriology (Table 1). 
Table 1. Morphological and biochemical Characterization of selected Bacterial cultures.

\begin{tabular}{|c|c|c|c|}
\hline \multirow{2}{*}{ Morphological Test } & \multicolumn{3}{|l|}{ Bacterial Isolates } \\
\hline & Bacillus sp. & Pseudomonas sp. & E. coli \\
\hline Colonies appearance & Convex, smooth, transparent & $\begin{array}{l}\text { Colourless, convex, smooth, } \\
\text { fluorescent, circumference }\end{array}$ & $\begin{array}{l}\text { Transparent colonies, smooth } \\
\text { margin, convex }\end{array}$ \\
\hline Negative staining & Small rod, arranged inchain & Short rod & Cocci, diplococci, rod, \\
\hline Gram staining & Gram-positive & Gram-negative & Gram-negative \\
\hline \multicolumn{4}{|l|}{ BIOCHEMICAL TEST } \\
\hline Oxidase & Negative & Positive & Positive \\
\hline Methylred ( MR) & Negative & Negative & Positive \\
\hline VogesProskaur (VP) & Positive & Negative & Negative \\
\hline Oxidative Fermentation (OF) & Positive & Positive & Positive \\
\hline Indole & Negative & Negative & Positive \\
\hline Citrate & Positive & Positive & Negative \\
\hline Urease & & Negative & Negative \\
\hline Nitrate Reduction (NR) & Positive & Positive & Positive \\
\hline Hydrogen Sulphide production & & Negative & Negative \\
\hline Gas & Negative & Positive & Positive \\
\hline Catalase & Positive & Positive & Positive \\
\hline \multicolumn{4}{|c|}{ CARBOHYDRATE UTILIZATION TEST } \\
\hline Glucose & Positive & Negative & Positive \\
\hline Fructose & Positive & Negative & Negative \\
\hline Maltose & Positive & Negative & Negative \\
\hline Lactose & Variable & Negative & Positive \\
\hline Sucrose & Positive & Sucrose & Variable \\
\hline Arabinose & Positive & Negative & Positive \\
\hline Mannitol & Positive & Positive & Negative \\
\hline
\end{tabular}

\subsection{Biosynthesis of Silver Nanoparticles}

The biosynthesis of silver nanoparticles were investigated using both biomass and supernatant separately primarily through the observation of colour change of the experimental sample in the presence of $1 \mathrm{mM}$ of $\mathrm{AgNO}_{3}$. A colour change from pale yellow to brown occurred in both bacterial biomass and supernatant within $24 \mathrm{~h}$. The positive result as observed by the formation brown colour was maintained throughout the $72 \mathrm{~h}$ (not shown). At the same time, experimental control containing heat killed biomass or supernatant without silver nitrate showed no colour change (not shown). The visual change of colour from yellow to reddish brown might be due to excitation of surface plasmon resonance in silver nanoparticle s[16, 18]. Even though the colour change was observed for sample containing, both biomass and supernatant, however further experiments were continued with extracellular samples due to comparative advantage of extracellular better synthesis over intracellular fraction.

\subsection{Characterization of Synthesized Silver Nanoparticles}

The synthesized silver nanoparticles were then characterized by UV spectrophotometer. The UV-visible spectra recorded at different time intervals showed increased absorbance with increasing time of incubation. The absorbance spectra of reaction mixture containing aqueous solution of $1 \mathrm{mM}$ silver nitrate and the pellet ofselected bacterial isolatesafter incubation. The bands corresponding to the surface plasmon resonance were observed between 410 to $430 \mathrm{~nm}$ employing spectrophotometrically [19]. However, the peak was observed at $420 \mathrm{nmwas}$ evident of the presence of silver nanoparticlesin both bacterial culture supernatant and biomass (Figures $1 \mathrm{a}, \mathrm{b}$ ). Similar to our findings, other researchers have also reported the formation of silver nanopartícles by exhibiting the typical surface plasmon absorption maxima at nearly $420 \mathrm{~nm}$ from the UV-Vis spectrum $[16,18,19]$.

The characterization of the silver nanoparticles was also investigated by analysing FTIR spectra. The spectral analyses were done for control (Figure 2a) and experimental samples (Figure 2b) using FTIR spectroscopy. The absorption spectra observed also showed the presence of the silver nanoparticles in bacterial culture supernatant (Figure 2b). The mechanism for silver nanoparticles biosynthesis involves nitrate reductase enzyme [20]. The bands observed between 1000 $\mathrm{cm}-1$ to $1600 \mathrm{~cm}-1$ might be due to stretching vibrations of $\mathrm{C}=\mathrm{O}, \mathrm{C}-\mathrm{N}$ and $\mathrm{O}-\mathrm{H}$ functional groups, respectively. Other researchers also reported similar findings. Mohanta et al. [13] also reported that the $\mathrm{C}=\mathrm{O}$ and $\mathrm{C}-\mathrm{N}$ stretching which are usually found in the proteins involve in the reduction of the metal ions. The findings revealed that the above functional groups might play role in silver nanoparticles synthesis. 


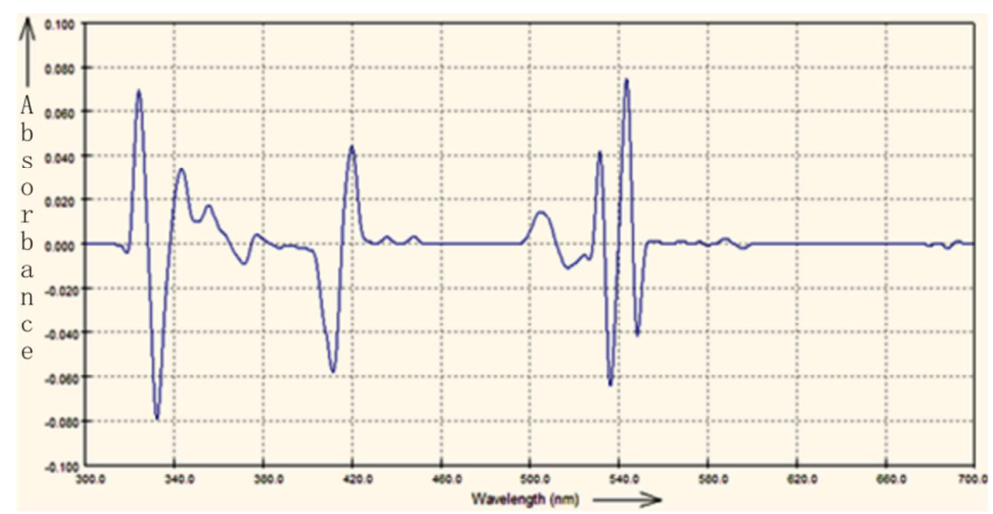

a.



b.

Figure 1. UV-Vis absorption spectra of Pseudomonas sp. (a) biomass and (b) culture supernatant after $24 \mathrm{~h}$ incubation (showing the presence of silver nanoparticles).
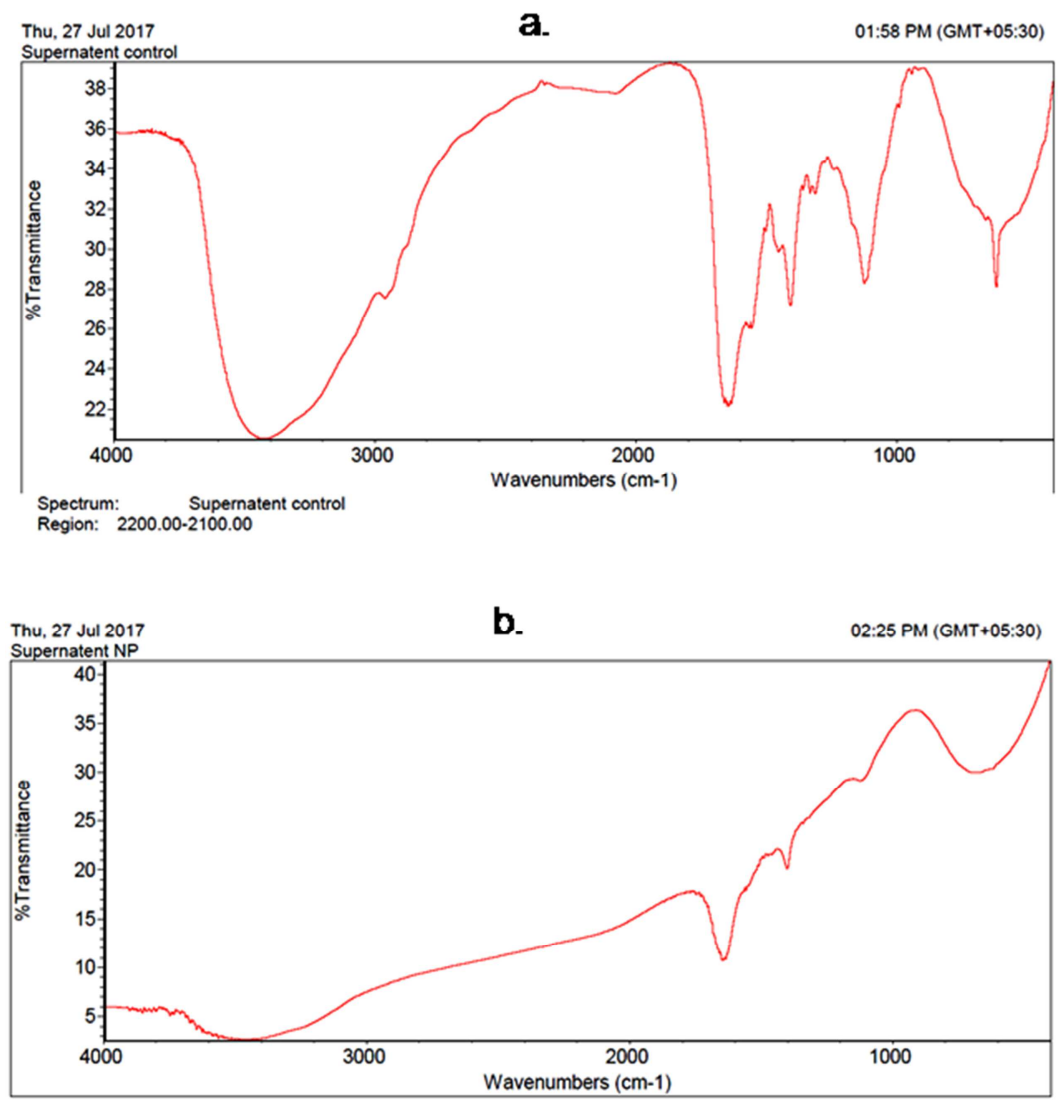

Figure 2. FTIR spectra recorded with synthesized silver nanoparticles in bacterial supernatant, (a) experimental and (b) control sample. 


\subsection{Antibacterial Effect of Silver Nanoparticles}

Silver and its derivatives are widely used in medicine for a long time in the treatment of bacterial infections. Discs diffusion test was performed for Staphylococcus sp. using different antibiotics. The bacterium was resistant to all tested antibiotics. However, Staphylococcus sp. was found to be sensitive for the most of tested antibiotic (doxycyclin, ciprofloxacin and ceftazidime) when silver nanoparticles impregnated antibiotic discs were used compared to nonimpregnated discsonMueller Hinton Agar medium (Table 2). Other researcher also investigated the antibacterial property of silver nanoparticles against multidrug resistant organisms [21]. The mechanism of the bactericidal effect of silver nanoparticles is not well-known. Whereas silver nanoparticles may attach to the surface of cell membrane, and disturb its physiological functions [18]. However, many researchers proposed the possible mechanisms of antibacterial effect of silver nanoparticles such as inactivation of main cellular proteins, impairment of genetic materials and enzyme degradation by silver ions [22, 23].

Table 2. Antimicrobial activity of silver nanoparticles against multiple antibiotic resistant Staphylococcus sp.

\begin{tabular}{lll}
\hline \multirow{2}{*}{ Antibiotics } & Results & Silver nanoparticles impregnated antibiotic disc \\
\cline { 2 - 3 } & Antibiotic disc & Sensitive \\
\hline Doxycyclin (DO) & Resistant & Sensitive \\
Ciprofloxacin (CIP) & Resistant & Sensitive \\
Ceftazidime (CAC) & Resistant & \\
\hline
\end{tabular}

\section{Conclusions}

The present study emphasizes the use of bacteria for silver nanoparticles synthesis with potent biological effect such as characterization of silver nanoparticles having antibacterial activity. The silver nanoparticles were synthesized in both bacterial biomass and culture in the presence of $1 \mathrm{mM}$ of $\mathrm{AgNO}_{3}$. The characterization of silver nanoparticles synthesized by Pseudomonas sp. was observed by absorbance spectra using UV-Vis and FTIR spectrophotometry. The synthesized nanoparticles were made sensitive to antibiotics for which the isolate Staphylococcus sp. was previously resistant before amendment of silver nanoparticles. The study suggested the possible use of microbially synthesized silver nanoparticles against antibiotic resistant bacteria which is a major public health concern.

\section{References}

[1] Aguilar-Méndez AM, Martı'n-Martı'nez ES, Ortega-Arroyo L, Cobia'n-Portillo G, Sa'nchez-Espi'ndola E (2010) Synthesis and characterization of silver nanoparticles: effect on phytopathogens Colletotrichum gloesporioides. J Nanopart Res 13: 2525-32.

[2] Nowack B, Krug HF, Height M (2010)120 years of nanosilver history: implications for policy makers. Environ SciTechnol45: 1177-1183.

[3] Petit C, Lixon P, Pileni MP (1993) J Phys Chem 97:1297412983.

[4] Husseiny MI, El-Aziz MA, Mahmoud MA (2007) Biosynthesis of gold nanoparticle using Pseudomonas aeruginosa. SpectrochemActa A MolBiomol Spectro 67: 1003-1006.

[5] Alarcon EI, Udekwu K, Skog M, Pacioni NL, Stamplecoskie KG, González-Béjar M et al. (2012) The biocompatibility and antibacterial properties of collagen-stabilized, photochemically prepared silver nanoparticles.
Biomaterials33: 4947-4956.

[6] Khan Z, Al-Thabaiti SA, Obaid AY, Al-Youbi AO (2011) Preparation and Characterization of Silver Nanoparticles by Chemical Reduction Method. Colloids and Surfaces B: Biointerface82: 513-517.

[7] Reicha FM, Sarhan A, Abdel-Hamid MI, El-Sherbiny IM (2012) Preparation of Silver Nanoparticles in the Presence of Chitosan by Electrochemical Method. Carbohydrate Polymers89: 236-244.

[8] Sharma VK, Yngard RA, Lin Y (2009) Silver nanoparticles: green synthesis and their antimicrobial activities. AdvCollIntSci145: 83-96.

[9] He S, Guo Z, Zhang Y, Zhang S, Wang J, et al (2007) Biosynthesis of gold nanoparticles using the bacteria Rhodopseudomonas capsulata. Materials Lett 61: 3984-3987.

[10] Ahmad A, Mukherjee P, Senapati S, Mandal D, Khan MI, Kumar R, et al (2003). Extracellular biosynthesis of silver nanoparticles using the fungus Fusariumoxysporum. Colloids Surf B Biointerfaces 28:313-318.

[11] Mohanta Y, Panda S, Biswas K, Tamang A, Bandyopadhyay J, De D, et al (2016) Biogenic synthesis of silver nanoparticles from Cassia fistula (Linn.): in vitro assessment of their antioxidant, antimicrobial and cytotoxic activities. IET Nanobiotechnol. 10: 438-444.

[12] Mohanta YK, Panda SK, Bastia AK and Mohanta TK (2017) Biosynthesis of silver nanoparticles from Protiumserratumand investigation of their potential impacts on food safety and control. Front. Microbiol. 8:626.

[13] Nayak D, Pradhan S, Ashe S, Rauta PR, Nayak B (2015) Biologically synthesized silver nanoparticles from three diverse family of plant extracts and their anticancer activity against epidermoid A431 carcinoma. J Colloid Interface Sci 457: 329-338.

[14] Nair R, Varghese SH, Nair BG, Maekawa T, Yoshida Y, Sakthi KD (2010) Nanoparticulate material delivery to plants. Plant Sci179: 154-163.

[15] Holt JG (1994) Bergeys Manual of Determinative Bacteriology. ${ }^{\text {th }}$ Edn., Williams and Wilkins, Baltimore. 
[16] Shivakrishna P, Krishna M, Charya M (2013) Synthesis of Silver Nano Particles from Marine Bacteria Pseudomonas aerogenosa. Octa J Biosci 1(2): 108-114.

[17] Saifuddin N, Wang WC, NurYasumira AA (2009) Rapid biosynthesis of silver nanoparticles using culture supernatant of bacteria with microwave irradiation. Euro J Chem 6:61-70.

[18] Guzman MG, Dille J, Godet S (2009) Synthesis of silver nanoparticles by chemical reduction method and their antibacterial activity. Int J ChemBiomolEng 2:3.

[19] Chung IM, Park I, Seung K, Thiruvengadam M, Rajakumar G (2016) Plant-mediated synthesis of silver nanoparticles: their characteristic properties and therapeutic applications. Nanoscale Res Lett 11: 40.

[20] Kumar V, Yadav SC, Yadav SK (2010) Syzygiumcumuni leaf and seedextract mediated biosynthesis of silver nanoparticles and their characterization, $\mathrm{J}$ ChemTechnol Biotechnol 85(10):1301-1309.

[21] Rai M, Yadav A, Gade A (2009) Silver nanoparticles as a new generation of antimicrobials. BiotechnolAdv 27: 76-83.

[22] Guzman M, Dille J, Godet S (2012) Synthesis and antibacterial activity of silver nanoparticles against Grampositive and Gram-negative bacteria. Nanomed NanotechnolBiol Med 8: 37-45.

[23] Patra JK, Baek KH (2017) Antibacterial activity and synergistic antibacterial potential of biosynthesized silver nanoparticles against food borne pathogenic bacteria along with its anti candidal and antioxidant effects. Front Microbiol 8:167. 